\title{
The Consumer Scam: An Agency-Theoretic Approach
}

\author{
Sareh Pouryousefi ${ }^{1} \cdot$ Jeff Frooman $^{2}$
}

Received: 12 January 2016/ Accepted: 8 February 2017/Published online: 7 March 2017

(C) The Author(s) 2017. This article is published with open access at Springerlink.com

\begin{abstract}
Despite the extensive body of literature that aims to explain the phenomenon of consumer scams, the structure of information in scam relationships remains relatively understudied. The purpose of this article is to develop an agency-theoretic approach to the study of information in perpetrator-victim interactions. Drawing a distinction between failures of observation and failures of judgment in the pre-contract phase, we introduce a typology and a set of propositions that explain the severity of adverse selection problems in three classes of scam relationships. Our analysis provides a novel, systematic explanation of the structure of information that facilitates scam victimization, while also enabling critical scrutiny of a core assumption in agency theory regarding contract design. We highlight the role of scam perpetrators as agents who have access to private information and exercise considerable control over the terms and design of scam relationships. Focusing on the consumer scam context, we question a theoretical assumption, largely taken for granted in the agency literature, that contact design is necessarily in the purview of the uninformed principal.
\end{abstract}

Keywords Consumer scam - Fraud - Agency theory · Information asymmetry $\cdot$ Adverse selection $\cdot$ Contract design

Sareh Pouryousefi

sareh.pouryousefi@nottingham.ac.uk

Jeff Frooman

frooman@unb.ca

University of Nottingham, Nottingham NG8 1BB, UK

2 University of New Brunswick, Fredericton, NB E3B 5A3, Canada

\section{Introduction}

Would you believe the authors of this paper are former Nigerian generals who will soon contact you by email regarding 45 million dollars we had to leave behind when we fled the country? The money comes from our investments in offshore oil. If you can send us $\$ 1000$, we are prepared to pay you $\$ 200,000$. Your money will be pooled with that of others to pay our agents to enter Nigeria and bring out the money, which is hidden just inside the border. Absurd? It turns out that in 2015 alone, 1.2 million individuals fell victim to scams in the U.S., accounting for an estimated loss of $\$ 765$ million (FTC 2016). Consumer scams involve the deception of individuals who voluntarily choose to participate in an exchange on the promise of receiving tangible or intangible goods, services, or financial returns that are never to be provided or are grossly misrepresented (NFA 2013). Product, service, Ponzi, and email scams are examples of this increasingly pervasive class of transactions that manipulate victims in modern developed economies.

Over the past three decades, the individual characteristics of consumer scam perpetrators and their victims have been the subject of extensive, multidisciplinary debate. Age, nationality, culture, psychological disposition, irrationality, and cognitive bias have been proposed as core individual-level explanations by psychologists, behavioural economists, and criminologists (Lea et al. 2009; Mears et al. 2014; Tippett 2014). Distinct scam contexts, such as dating scams (Whitty and Buchanan 2012; Whitty 2013), written communication scams (Carter 2015), email scams (Isacenkova et al. 2014; Konte et al. 2009), and online auction scams (Aleem and Antwi-Boasiako 2011; Ramesh et al. 2014; Wall 2007), have also received attention, along with investigations into regional specifications-e.g. within 
the USA and Australia (Langton and Baum 2010; ABS 2012).

In addition to individual-level and context-specific studies, others have focused on scam structure more generally, though this literature is relatively sparse. This research analyses scams as a function of the relationship between individual victims and perpetrators, focusing, for example, on interactions between victims and perpetrators (Button et al. 2009; Langenderfer and Shimp 2001; Lea et al. 2009), and on the role of narrative (Akerlof and Shiller 2015; Langenderfer and Shimp 2001; Whitty 2015). The role of information has also received some attention, specifically in relation to investment scams (Chen et al. 2016; Evans et al. 2013; Ghent et al. 2016).

Despite these recent contributions, the study of information in the literature on consumer scams remains largely a background feature and a "sideshow", as opposed to a pivot of inquiry (Akerlof and Shiller 2015: 166). Little academic work systematically examines the structure of information in consumer scams. This is especially so during the initial, pre-contract phase, when perpetrators design their schemes and make contact with potential victims. Understanding the structure of information in this initial phase is important, since a well-designed scam can take advantage of asymmetric information to bait prospective victims, irrespective of individual characteristics, cognitive capacities, and contextual variations. In other words, given the right scam design, it is possible to scam perfectly rational victims.

The purpose of this article is to highlight the perpetrators' role in controlling and manipulating information in their interaction with prospective victims. We draw on agency theory to carry out our examination of consumer scams. In a principal-agent model, two parties interact, one party (the agent) acts "on behalf of" the other (the principal), and the agent "is supposed to advance" the principal's goals (Milgrom and Roberts 1992, p. 170). In a principal-agent model of consumer scams, the informed perpetrator (agent) carries out a task on behalf of the uninformed victim (principal), and the perpetrator aims to appear as though they are promoting the victim's goals. Since information asymmetries often exist before the scam interaction begins, scam victims face an adverse selection problem. We introduce three classes of adverse selection relationships between scam perpetrators and victimsblind-spot, homoious hemin, and wardship. Drawing on a distinction between "observation" and "judgment" (Mitnick 1996) in the pre-contract structure of information, we generate a set of propositions about the relative severity of adverse selection, and, ceteris paribus, the relative opportunities for perpetrators to carry out scams.

Our analysis of scams through the lens of agency theory highlights core features of the structure of information that facilitate scam victimization. Beyond shedding new light on the phenomenon of consumer scams, this article also offers a vantage point from which to critically evaluate a core assumption that has not yet received much attention in the literature on agency theory. As we demonstrate, in their roles as informed agents, perpetrators manipulate uninformed victims by convincing them to enter adverse selection relationships. Failures of observation and/or judgment are intentionally embedded into these adverse selection settings. The victim's (principal's) role in contract design is thus reduced to a symbolic function, while the perpetrators exercise genuine influence over the interaction. In contrast, in the standard principal-agent model, uninformed principals are assumed to be in charge of contract design. In this manner, our work scrutinises the nature of contract design in consumer scams alongside other applied contexts, e.g. professional services, where the agency-theoretic assumption of contract design has received similar critical attention (Sharma 1997).

Our article is structured as follows: The "Agency Theory: Overview" Section provides a theoretical overview of agency theory, followed by a definitional discussion of consumer scams in the "Consumer Scam: Our Definition" Section. In the "Perpetrators as Agents" Section, we propose a typology of core consumer scam relationships and generate three propositions regarding the severity of adverse selection and the opportunities to carry out scams. The "Adverse Selection Severity and Relative Opportunities to Carry Out Scams" Section puts forward a typology of adverse selection relationships, and the "Contract Design, Consumer Scams, and the Principal-Agent Model" Section discusses contract design in consumer scams and its implications for the literature on agency theory.

\section{Agency Theory: Overview}

Agency theory is a dominant approach in the economic study of organization and management. A comprehensive review of the multidisciplinary literature on agency theory is beyond the scope of this paper-see Mitnick (1992) for an overview of the theory's prominent ancestry, Pratt and Zeckhauser (1985) for a general introduction, Laffont and Martimort (2009) and Salanié (2005) for game- and contract-theoretic overviews, Eisenhardt (1989) for a management and organization theory introduction, and Heath (2009) for a discussion of common theoretical abuses. Our approach to agency involves the application of game theory to the analysis of principal-agent interactions. This stream of agency theory has sometimes been referred to as the "principal-agent" approach (Jensen 1983) or the "risk and asymmetric information" approach (Mitnick 1992, p. 79), 
given the dominant role of information economics and of agency risks in this literature. Below, we provide a partial overview of the basic features of this approach as they pertain to our current investigation.

A principal-agent model consists of two parties. One party (the principal) designs a contract, making a take-itor-leave-it offer to the other party (the agent). The contract constitutes the implicit or explicit agreement of the terms of interaction between the two parties. If the terms of the contract are agreed upon, the agent is supposed to carry out a service on behalf of the principal and in return receive some compensation. Principals are by definition assumed to have the bargaining power to dictate the terms of the contract. The principal's task is to design a compensation scheme that attracts a sufficiently capable agent and efficiently motivates her to deliver high-quality services.

Making this compensation decision is a non-trivial exercise for principals given certain background conditions. We mention only three essential conditions here: goal incongruity, information asymmetry, and contract design. ${ }^{1}$ Goal incongruity in the principal-agent interaction results when the agent and the principal have different or conflicting interests, and so the agent's preference regarding performance of services does not match the principal's preference. Information asymmetry results when, in comparison with principals, agents possess superior information regarding their own abilities, preferences, effort levels, and services. In other words, agents have access to private information-information that is not available to principals. This can be problematic because the principal-not the agent-is in charge of contract design: the principal makes decisions regarding the structure and terms of interactions, and extends a take-it-or-leave-it offer to the agent. The agent then decides whether to accept or reject the contract. Thus, the principal is supposed to exercise influence over defining the terms of the interaction, but her task becomes difficult when the agent has divergent interests and has access to private information.

Consumer scams are an ideal context for the study of principal-agent models, since perpetrators have an information advantage over naïve prospective victims. Further, perpetrators and victims' interests are incongruent-the former wins at the expense of the latter in a successful scam. As we will demonstrate, however, while principals are supposed to design the contract and set the terms of the interaction according to the principal-agent model, this role assignment is reversed in the context of consumer scams. Perpetrators (agents) exercise influence over their

\footnotetext{
${ }^{1}$ Other core assumptions in this stream of agency theory are riskaversion on the part of agents and the presence of uncertainty (Arrow 1985; Dees 1992). We do not discuss these and other background conditions since our argument does not address them directly.
}

prospective victims instead. We elaborate on this feature of the consumer scam principal-agent relationship in the remainder of the paper.

\section{Consumer Scam: Our Definition}

A consumer scam involves an intention to deceive an individual who chooses to participate in an exchange on the promise of receiving tangible or intangible goods, services, or financial returns that are never to be provided or are grossly misrepresented (FBI 1984; NFA 2013; OFT 2006; Titus and Gover 2008). The terms "fraud", "con", and "swindle" are typically used synonymously with "scam". Product scams involving tangible goods include "miracle" health cures and phony gemstones, and also fraudulent lotteries, prize draws, sweepstake games, and auction sites (Chua and Wareham 2008). Product scams involving intangible goods include bogus job offers and work-fromhome arrangements, as well as dating scams that romance victims and coax them into sending money to potential marriage partners. Service scams include fake psychics and home repairs (Cohen 2006; Levi 2008). Scams that promise financial returns include "Nigerian 419" advance-fee scams that persuade individuals to part with money in anticipation of larger returns (Smith 2009), and Ponzi or pyramid schemes that use early investors to recruit subsequent investors, with the contributions of the latter used to pay off the former (Frankel 2012; Trahan et al. 2005). All of these scams also lend themselves to online implementation, and the internet has become the predominant domain for scamming (Cross et al. 2014).

According to Akerlof and Shiller (2015), all deceptive or manipulative economic activity that gets people to do something that is not in their own interest is fraudulent, as it involves "phishing" (scamming) for "phools" (victims). Under their broader definition of fraud, one can include scams that reach far beyond consumers. Examples include scams involving academic dishonesty (e.g. students cheating or falsifying applications, university professors misrepresenting research results), lying on mortgage or job applications, embezzlement, employee theft, medicare fraud, and tax evasion (NFA 2013). These types of scam are beyond the scope of this paper.

Additionally, not all scams are directed at individuals. Some scams are carried out against private, public, or nonprofit institutions or collectives of individuals. To narrow our focus, we discuss only individual-level scams. Our study also does not apply to industry and market-level analyses, such as the subprime mortgage crisis or to deceptive advertising and lobbying practices. Finally, note that our definition stipulates that victims choose to participate in an interaction with the perpetrator. We do not focus 
on one-sided attacks, such as identity-theft schemes, phishing for people's passwords or account numbers, unauthorized billing of purchases, slamming (unauthorized switching of long-distance services by phone carriers), or the distortion of financial reports to confuse stockholders and potential investors.

\section{Perpetrators as Agents}

Consumer scam interactions share certain fundamental background assumptions and conditions with principalagent models. One typical feature is asymmetric information. In consumer scams, as well as principal-agent models, the agent has access to "private" information-useful information that is different and not worse than the principal's (Rasmussen 2007, p. 51). Principal-agent problems are subdivided into two categories- "adverse selection" and "moral hazard" (Arrow 1985; Laffont and Martimort 2009). In adverse selection problems, the agent is informed and the principal is uninformed prior to signing the agency contract (Bolton and Dewatriopont 2005; Hart and Holmström 1987; Husted 2007; Maskin and Riley 1984; Laffont and Martimort 2009; Rasmussen 2007; Salanié 2005). In consumer scams, information asymmetry often exists at the outset, before the scam interaction begins, so the victim faces an adverse selection problem. ${ }^{2}$ Consider an example from HR. Employers (principals) prefer to know about the talent, qualities, and potential of an employee (agent) before they hire her. The employer may propose a contractual arrangement to the potential employee. The potential employee knows her own ability, suitability, and opportunity costs from the start, but the employer does not have access to this information.

Adverse selection has great explanatory power and can be fruitfully applied to a range of social-scientific problems. To outline the structure of information in an accessible manner, we make a distinction between

\footnotetext{
${ }^{2}$ In technical terms, the problem of adverse selection is one of "hidden knowledge" (Arrow 1985). The agent has access to information that is not available to the principal (Laffont and Martimort 2009, pp. 12, 37). The principal moves first as a "Stackelberg leader" under asymmetric information, anticipating the agent's subsequent behaviour and optimizing accordingly within the available set of contracts (Laffont and Martimort 2009, p. 39; Salanié 2005 , p. 6). The principal faces moral-hazard problems if information is symmetric when the contract begins but becomes asymmetric afterwards. The problem of moral hazard typically is one of "hidden action" (Arrow 1985). The agent takes an action unobserved by the principal within a given contract (Laffont and Martimort 2009, p. 12). Consumer scams can involve both moralhazard and adverse selection problems, but given our emphasis on the structure of information that facilitate scams, this paper will focus on adverse selection.
}

"observation" and "judgment" (Mitnick 1996). ${ }^{3}$ Sometimes, the underlying issue in adverse selection is that the individual cannot "gather", "possess", or "monitor" certain kinds of information (Mitnick 1996). Other times, the foundational issue is that separate from whether the principal faces failures of observation, she fails to make an "evaluation" or "judgment" regarding the significance or relevance of information (Mitnick 1996). The principal cannot make sense of information about, for example, the agent's motivations and qualities, even when she has the relevant information at her fingertips, possibly because she lacks specialized knowledge or technical skills. ${ }^{4}$

In a consumer scam, perpetrators (agents) have access to private information. The interests of principals and agents are incongruent, and the motivations and characteristics of perpetrators (agents) cannot be adequately vetted by victims (principals). Prior to entering an interaction with perpetrators, victims may lack information about the perpetrators' relevant qualities and motivations (observation). Alternatively, victims may have access to relevant information regarding the perpetrator, but they may not be able to adequately evaluate the significance or relevance of this information (judgment). Depending on the specific consumer scam, observation, judgment, or both, can be relevant to the relationship. Table 1 presents a typology of the structure of information in adverse selection relationships based on a distinction between observation and judgment. ${ }^{5}$

It may appear that a necessary condition of judging a piece of information is the ability to observe it, and so it may seem that it is not possible to encounter a failure of judgment without at the same time encountering a failure of observation. But this is not what we mean by judgment. To clarify, consider a recent rental scam common in large metropolitan areas (Johnson 2016), whereby scammers rent an apartment for one night (e.g. on Airbnb) and then present themselves as the property owner trying to rent the

\footnotetext{
${ }^{3}$ Mitnick (1996) has argued that the failures of "observation" and "judgment" can be studied alongside each other as "defining dimensions to clarify different behavioural problems", including both moral hazard and adverse selection. In contrast, we draw on observation and judgment to highlight structural features of information within adverse selection. Although our use of these terms and the typology we produce in Table 1 bear a resemblance to and are inspired by Mitnick's (1996) work, we would caution readers against assuming them to be identical.

${ }^{4}$ Darby and Karni (1973) note that when contracting there are observation and judgment problems that make scams possible. They call these the experience and credence qualities of a good. However, their use of these concepts differs from ours in two ways. First, a good cannot exhibit both experience and credence qualities at the same time, as they're mutually exclusive. Second, the experience and credence qualities are relevant post-contract, but the focus of this article is pre-contract.

${ }^{5}$ To be clear, the failures of observation and judgment occur precontract and pertain to information, not behaviour.
} 
Table 1 Adverse selection relationships

\begin{tabular}{lll}
\hline & Principal can judge information & Principal cannot judge information \\
\hline Principal can observe information & Symmetric information & Homoious Hemin \\
$\begin{array}{l}\text { Principal cannot observe } \\
\text { information }\end{array}$ & Blind-spot & Wardship \\
\hline
\end{tabular}

property long-term via another venue (e.g. Craigslist). The scammer shows the property to unsuspecting, prospective renters, and, if they are interested, asks for them to transfer a deposit to their account. By the time the renters realize that this is not the actual owner and that they will not be acquiring the property, their money is long gone. One may be experienced in renting apartments, and thus have considerable expertise when it comes to judging a rental's desirability and value. But in this case, the inability to observe certain information (e.g. the true owner, the actual status of the property, etc.) creates the problem. We discuss the structure of "can judge but cannot observe" cases, along with two other kinds of scam relationship, in more detail below.

\section{Wardship Relationships}

When an uninformed victim (principal) fails to observe and also fails to judge information prior to contracting, she is in a wardship relationship. The victim fails to gain access to relevant information, and at the same time cannot properly evaluate or understand the information that she does possess. In comparison with a symmetric information model, wardship interactions exhibit severe adverse selection. The perpetrator (agent) is the party who has access to private information, and she can design a wardship relationship with prospective victims.

Proposition 1 In the wardship relationship, where the principal cannot observe and cannot judge, adverse selection is severe. Ceteris paribus, this design offers ample opportunities for perpetrators to carry out scams.

Consider the Canadian mining company, Bre-X. Starting in 1995, Bre-X began promoting the Busang gold mine despite minimal evidence about the presence of the precious metal. The Busang mine was located in the equatorial jungle on the Indonesian island of Borneo, a place so remote that anthropologists study the indigenous tribes because of their infrequent contact with the outside world. When the company claimed that Busang held 71 million ounces of gold, hundreds of thousands of investors put their savings into the venture and the Bre- $\mathrm{X}$ share price rose exponentially (Francis 1997; Goold and Willis 1997). For these investors, the Busang mine's location posed a challenge of observation, while their ignorance about mining investments posed a challenge of judgment. Eventually, when a joint venture was announced to extract the gold, other mining companies entered the picture (Hutchinson 1998). One partner was Freeport McMoran Corporation, which already had operations in Indonesia. They sent some of their mineralogists to Busang to test samples from the site. Thus, post-contract the relationship shifted from wardship to a symmetric information structure. No gold was found. Within a couple of days, $\$ 5$ billion worth of stock value in the joint venture had been lost, and Bre-X was forced into bankruptcy (Naylor 2007).

In this kind of scam, if an investor cannot observe and judge relevant information prior to the commencement of a contract, then adverse selection is severe. In modern times, most gold readily accessible to prospectors has already been found and extracted, and so the task of prospecting for new veins is a laborious and inexact process. Thus, success stories in gold mining often begin the way Bre-X didwith the sudden discovery of gold in a very remote location. It was plausible that Bre-X genuinely had the potential to produce profits. Given the complications of mineral exploration, and in the absence of third-party survey reports prior to commencing the contract, the perpetrators were in a position to design an interaction with victims that had severe adverse selection so that both observation and judgment were impaired. Since perpetrators can exercise considerable control over the structure of information in wardship relationships, they have a good opportunity to lure their prospective victim into the scam.

\section{Homoious Hemin Relationships}

When an uninformed victim (principal) cannot judge but can observe, she finds herself in a homoious hemin relationship. While the victim appears to possess the relevant information she needs about the perpetrator prior to contracting, she fails to decipher it or make sense of its significance. $^{6}$ In comparison with symmetric information

\footnotetext{
${ }^{6}$ In Plato's parable of the cave, the den dwellers can see, but cannot understand what they see. What they can sense with their eyes are phenomena, which are, at best, only representational of the noumenal realm beyond. Socrates says these den dwellers are "like ourselves" (homoious hemin), suggesting that their status is indicative of the human condition, i.e. seeing but not comprehending (Plato, Republic VII, 515a5). And while we do not wish to make any such sweeping epistemological claim that people see (observe) but do not understand (judge), we think Plato's parable can aptly characterize this one cell of our typology.
} 
interactions, homoious hemin involves moderate adverse selection. The perpetrator (agent) is the party who has access to private information, and she can design a homoious hemin relationship with prospective victims.

Proposition 2 In the homoious hemin relationship, where the principal can observe but cannot judge, adverse selection is moderate. Ceteris paribus, this design offers moderate opportunities for perpetrators to carry out scams.

An example of homoious hemin is the sale of phony gemstones. Consider Jack Hasson, a con man who worked out of West Palm Beach, Florida. He sought out wealthy clients on golf courses, who were interested in purchasing precious jewels, usually both as an expensive gift and as an investment. Two of his clients were professional golfers Jack Nicklaus and Greg Norman. The gemstones Hasson sold were very high quality replicas, good enough to fool anyone but a professional appraiser, but worth only about $10 \%$ of their quoted value. The gemstones bore certificates ostensibly from Bvlgari, Cartier, Tiffany, and other credible premium jewellers, but were printed from Hasson's computer. Before commencing their relationship, Hasson would typically loan a few genuine stones to prospective clients, and encourage them to take the gems in for appraisal. Once their quality was confirmed, Hasson would then begin to sell his victims the fake gemstones (Naylor 2010). The relationship was thus structured as homoious hemin, involving the problem of judgment.

Sooner or later, someone with expertise in the good being provided would be drawn in. Either the perpetrator mistakenly approached such a person as a potential victim, or a current victim would boast to the expert, or try to do them a good turn by bringing them in on the deal. On the few occasions when he was caught, Hasson would pretend mortification, take back the jewels, and issue a complete refund to placate the customer. These refunds amounted to merely a minor inconvenience to Hasson as long as he was allowed to continue operating. Nicklaus and Norman each spent about $\$ 500,000$ on Hasson's fake gemstones, the latter on stones worth less than $\$ 10,000$ (Naylor 2010). The scam finally came to an end during a routine insurance appraisal of Nicklaus's property (Lambert 2000; US v. Hasson 2003; Wilson 2000). Since perpetrators can exercise a fair degree of control over the structure of information in homoious hemin relationships, they have a moderate opportunity to lure their prospective victim into the scam.

\section{Blind-Spot Relationships}

When an uninformed victim (principal) cannot observe but can judge, she finds herself in a blind-spot relationship. Here, the victim does not have access to or cannot observe relevant information prior to contracting. The victim has the capacity to fully evaluate and understand the information needed to make a good decision but she cannot observe, so there is a gap in her information set. In comparison with symmetric information interactions, in blindspot interactions, adverse selection is moderate. The perpetrator (agent) is the party who has access to private information, and she can design a blind-spot relationship with prospective victims.

Proposition 3 In the blind-spot relationship, where the principal cannot observe but can judge, adverse selection is moderate. Ceteris paribus, this design offers moderate opportunities for perpetrators to carry out scams.

Dating scams are a category of consumer scams that rely heavily on the failure of observation (Whitty and Buchanan 2012). About $85 \%$ of dating scams are run online (Ross and Smith 2011). The CEO of one dating site estimates that about $10 \%$ of dating profiles are fraudulent-not merely in regard to some trivial fact like the person's weight, but in their entirety (Murray 2013). "John Scofield", whose real identity is still not known, was one such perpetrator. Debbie Best of Montana fell for him. Best had dated throughout her adult life, but never married. Upon turning 50 , she decided it was time to try a dating site. John contacted her immediately, telling her she had a beautiful smile. They began their romance by corresponding on Facebook and over the phone. However, she was never able to meet him directly. The pre-contract information structure of interaction was thus blind-spot, since given Best's dating experience she may have not entered this interaction if she had had access to more information about Scofield than was available from his online dating profile.

Sometime after Best's interaction with Scofield began, requests for money were made, first in small amounts, and then for increasing sums. Scofield even told Best a story about needing money to travel back from Nigeria where he had gone to buy artefacts for his antique shop. According to one study, the average financial loss for dating victims was $\$ 17,500$, with scams averaging three months in length (Ross and Smith 2011). Best beat the odds, losing only $\$ 1500$ before cluing into Scofield's scam (Best 2012). Once Scofield's actions began to be perceived as suspicious by Best, she recognized that she had been missing some critical information before entering the relationship. Scofield had access to private information prior to commencing the interaction and had used the online dating platform to design a blind-spot relationship. Since perpetrators can exercise a fair degree of control over the structure of information in blind-spot relationships, they have a moderate opportunity to lure their prospective victims into the scam. 


\section{Adverse Selection Severity and Relative Opportunities to Carry Out Scams}

Bre-X, the phony gemstones, and the dating scam can now be compared in view of their relative adverse selection severity and the relative opportunities for perpetrators to carry out scams. Due to the failures in observing and judging information, adverse selection in wardship (Bre-X) is the most severe. The jewellery and dating scams exhibit relatively moderate levels of adverse selection, since they each involve only one of the failures of judgment or observation. In these examples, in comparison with Bre-X stockholders, victims can successfully judge or observe the claims made by perpetrators. Since failures of observation and judgment each pose separate, unique challenges, we do not make a comparative statement regarding the adverse selection severity of homoious hemin and blind-spot structures. A final note about "symmetric information": since neither the failures of observation nor judgment arise here, this relationship does not have the potential for adverse selection. Consider, Table 2, which is a variation of Table 1 (typology of adverse selection relationships) that includes scam-specific details.

This typology is informed by one of Mitnick's (1996) insightful contributions to agency theory-that information asymmetry is not a monolithic concept; rather, it involves a critical distinction between failures of observation and judgment. Our use of this distinction with respect to the structure of pre-contract information produces a finegrained analysis of the structure of information asymmetry as it pertains to consumer scams. With both observation and judgment in play, it is possible to see that varying levels of adverse selection exist in the three classes of relationships we have discussed. Perpetrators in turn have varying opportunities to carry out scams in these relationships, since they can design adverse selection scenarios that involve observation and judgment pitfalls.

This view stands in contrast to work on scams that has focused on psychological and cognitive behavioural variables. Personality traits, cognitive impairment (such as depression and dementia), cognitive bias, and bounded rationality have been highlighted in these mostly psychological findings. ${ }^{7}$ These studies, be they theoretical or empirical, tend to point in one direction-a failure of

\footnotetext{
7 Studies include personality traits such as fantasy proneness (Langenderfer and Shimp 2001; Whitty 2013), interpersonal influence susceptibility (Ganzini et al. 1990; Langenderfer and Shimp 2001; Naylor 2007), and social-status fulfilment (Fischer et al. 2013; Holtfreter et al. 2008; Ross and Smith 2011); cognitive impairment (Langenderfer and Shimp 2001; Pinsker et al. 2011), and cognitive biases (Cialdini 2007; Fischer et al. 2013; Gabaix and Laibson 2006; Kahneman and Tversky 1984).
}

human rationality-to explain the phenomenon of consumer scams.

Only a few articles have so far examined information asymmetry as an explanatory variable in consumer scams. These articles predominantly focus on investment fraud, and information asymmetry between investors and managers (e.g. Coric 2011; Evans et al. 2013; Ghent et al. 2016). ${ }^{8}$ This literature suggests that scam victimization may not necessarily involve a failure of human rationality. Rather, scams can be explained as involving a deficit in serviceable information. The point is simple, but worth emphasizing: when information is asymmetric, it is possible to scam perfectly rational victims. This paper's three proposed classes of adverse selection relationships have established a theoretical account of this position. We do not think that psychological variables are unimportant, but consumer scams may sometimes be as much about informational asymmetries as about failures of rationality. Our typology of adverse selection relationships in consumer scams promotes the study of information in scams generally, beyond the specific context of investments fraud, where the topic has begun to receive some attention.

\section{Contract Design, Consumer Scams, and the Principal-Agent Model}

So far, we have drawn on the principal-agent model to study the structure of information that facilitates consumer scams. We now consider whether the principal-agent model itself can be critically evaluated in view of its applicability to consumer scams. Agency theory has a number of background conditions and assumptions that affect its application. In the "Agency Theory: Overview" Section, we mentioned three of these conditions: asymmetric information, goal incongruity, and contract design. As we saw in the "Perpetrators as Agents" and "Adverse Selection Severity and Relative Opportunities to Carry Out

\footnotetext{
${ }^{8}$ Less-informed investors are exploited by better-informed managers when the latter are quick to release good news and slow to release (or actually conceal) bad news about a firm (Kane 2003). Additionally, investors have been defrauded when a firm's finances are complicated by balance-sheet items that do not yet have standardized accounting procedures governing their reporting (Nwogugu 2004), when they involve numerous diversified operations creating a labyrinthian flow of the firm's finances (Ghent et al. 2016), or when they involve arcane laws (Coric 2011). Similarly, investment fraud has been associated with newer securities that lack sufficient history to establish risk profiles (Akerlof and Shiller 2015), or more-established securities that trade too infrequently to gather sufficient statistics on them (Evans et al. 2013). Outside the investments literature, Kurland (1991) discusses how information asymmetry may lead to opportunism in the case of commissioned sales agents who have goals (due to their incentive structure) that may conflict with the principals (customers) they serve.
} 
Table 2 Victim-perpetrator adverse selection relationships

\begin{tabular}{lll}
\hline & Victim can judge information & Victim cannot judge information \\
\hline $\begin{array}{l}\text { Victim can observe } \\
\text { information }\end{array}$ & Symmetric information & $\begin{array}{c}\text { Adverse selection Opportunity for scam }=\text { moderate } \\
\text { (precious gemstones) }\end{array}$ \\
$\begin{array}{l}\text { Victim cannot observe } \\
\text { information }\end{array}$ & $\begin{array}{c}\text { Adverse selection Opportunity for scam = moderate } \\
\text { (dating scam) }\end{array}$ & \begin{tabular}{c} 
Adverse selection/opportunity for scam $=$ severe $($ Bre-X) \\
\hline
\end{tabular}
\end{tabular}

Scams" Sections, asymmetric information and goal incongruity unproblematically apply to the study of consumer scams. We now discuss the applicability of contract design, the third key element in the principal-agent model, to understanding consumer scams.

In agency theory, principals are uncontroversially defined as the party in charge of designing and outlining the principal-agent contract (Laffont and Martimort 2009; Bergen et al. 1992; Bosse and Phillips 2016; Eisenberg 1976; Eisenhardt 1989; Fama 1980; Fama and Jensen 1983; Salanié 2005; Walsh and Seward 1990; White 1985). This assumption is shared across the various streams of agency theory. In this view, principal-agent relationships involve a top-down structure of interaction: the principal is defined as the dominant party who governs the agency interaction. The principal is in charge of designing the terms by which the agent carries out services on her behalf, not the other way around. This assumption about contract design is such an implicit part of the principal's role in the standard principal-agent model that the applied literature on agency theory for the most part does not identify it as a noteworthy background condition.

What do we know about contract design in the context of consumer scams? Does one party employ the other to carry out a service on her behalf? Yes, the victim hires, assigns tasks, or makes a similar sort of economic arrangement with the perpetrator, who is supposed to carry out certain tasks or services, and is purportedly supposed to promote the victim's interests. In the principal-agent model, the uninformed party is by definition the principal, and the informed party the agent. So the scam victim can be viewed as the uninformed principal who asks the informed perpetrator (agent) to carry out certain services. Notice, however, that in contrast to the standard principal-agent model, the victim (uninformed principal) is not the dominant party in charge of contract design. In fact, conversely, it is the informed perpetrator (agent) who schemes and designs the interaction and makes appropriate arrangements. In contrast to the standard model, where the principal (uninformed victim) should be in charge of contract design, the agent in consumer scams (informed perpetrator) is the party that exercises meaningful control over contract design in this context. We have established three variations in such control through our propositions about different adverse selection scam relationships.

The empirical literature on consumer scams confirms the dominant contract design status of informed perpetrators (agents). Consumer scams follow a recognizable modus operandi (Langenderfer and Shimp 2001), briefly summarized as follows: At the outset, experienced perpetrators script their work and map out the steps they need to take (Levi 2008). A narrative that accounts for the somethingfor-nothing benefits of the scam is composed (Akerlof and Shiller 2015). In the meantime, preparations may be made to provide or sell some genuine goods or services to build credibility for the operation. Well-planned scams even organize imitation customer-service units to handle complaints (Naylor 2010). To hook the victim, classic sales tactics, such as time-limited offers, reciprocation, and social proof (if others in your peer group are buying into a deal, it must be genuine) (Cialdini 1984) are employed. Scams are thus not unlike a legitimate, albeit aggressive, sales operation (Naylor 2010).

Perpetrators exercise influence over contract design and go one step further by misrepresenting the wage they deserve. The standard principal-agent model view puts principals in charge of designing contracts with only one constraint: the agent's compensation must equal or exceed the utility she would have received from her next bestknown alternative, i.e. her "reservation utility" (Rasmussen 2007). The value of the agent's reservation utility is typically stipulated in a given principal-agent model, and agents are assumed to refuse a contract that has an expected value below their reservation utility. In consumer scams, this means the victim is supposed to compensate the perpetrator with a wage that surpasses the perpetrator's next best alternative wage. To be sure, scam perpetrators are compensated much more handsomely than their reservation utility. Perpetrators lie, misrepresent facts, and manipulate their victims into believing that the services they promise to provide (if they are provided at all) are worth much more than they in fact are.

Thus, victims can hardly be said to have bargaining power or occupy a dominant role in the victim-perpetrator relationship. If victims believe they exercise genuine influence over the design of the scam contract, they are 
deluded. Within wardship, homoious hemins, and blindspot relationships, perpetrators present victims with a convincing, ready-to-use principal-agent mould - a narrative for how their interactions will be structured-and adverse selection is intentionally embedded within this mould. The victim's (principal's) contract design role is thus reduced to a symbolic function, while perpetrators exercise genuine influence over the interaction.

\section{Implication for Agency Theory}

The literature on agency theory is multidisciplinary and includes various approaches. The game-theoretic approach to agency theory that we have so far discussed in this paper pertains primarily to the problem of asymmetric information and agency risks in market interactions (Arrow 1963, 1985; Knight 1921; Marschak 1955; Ross 1973). A separate, dominant approach to agency is as a positive theory for analysing economic activities, predominantly focused on corporate governance and ownership issues within the firm (Alchian and Demsetz 1972; Fama 1980; Jensen and Meckling 1976). In this approach, a fundamental task of principals is to influence agents so that agency costs incurred by differing organizational goals and interests are limited (Eisenhardt 1989). While these two agency approaches have developed separately and have different trajectories, the more recent "ownership of the firm" literature on agency theory increasingly engages with the role of information. This involves examining when an agent's private information incurs agency costs and inefficiencies, and exploring optimal solutions that the principal may adopt to cope with the agent's opportunism in the face of asymmetric information (e.g. Bosse and Phillips 2016; Heath 2009).

When information is analysed in agency-theoretic settings, irrespective of differences in streams and approaches, agents are defined as the informed party and principals as the uninformed one. In the management and economic-organization literature, uninformed principals are commonly viewed as the dominant party (as owners, shareholders, CEOs, etc.) who set the terms of the interaction (e.g. Bosse and Phillips 2016; Eisenhardt 1989; Fama 1980; Fama and Jensen 1983; Jensen and Meckling 1976; Newton 1992; Walsh and Seward 1990). In the light of our discussion of consumer scams, however, we believe the matter of dominance over the terms and design of the principal-agent interaction requires critical treatment. The uninformed principal may control contract design formally, but the informal and implicit process of interaction may entail effective control by the informed agent, as in the context of the consumer scam. In other words, the agencytheoretic roles of principals and agents need not be associated with a fixed, explicit stance about dominance or control. A similar line of argument is supported by the work of certain agency scholars who separate organizational employment functions from agency roles (Husted 2007; Salanié 2005; Laffont and Martimort 2009). These scholars have called for a move beyond strict principal/ employer-agent/employee role assignments. Drawing on our agency-theoretic analysis of consumer scams, we believe this flexibility and revision should be extended beyond agency roles to agency authority and dominance. In other words, not only can agents take the role of employers, they can also exercise contract design control over the principal-agent interaction.

What would this flexibility around contract design entail for agency theory in the management and organization studies literature? Suppose the expert employee and her employer are facing a severe adverse selection problem. Who exerts control over the structure of this interaction? In the pre-contract stage, the potential employees may come up with ways to exert influence over contract design, given the prevailing adverse selection. In the market for hightech services, for example, it is not uncommon for specialists to approach businesses or individual consumers and provide them with solutions to the problems they did not know they faced. Take ads for apps or tools for managing information security, for example. These are in effect moulds and narratives for principal-agent relationships whereby the informed agent approaches the uninformed principal and offers to provide a service. Often the service recipient might not know she needs that service-the new updated Facebook app features, the novel Android pay function-until the service is offered to her. A more fluid stance about contract design and control over the terms of principal-agent interactions would enable us to analyse such settings using agency theory. This would help make systematic sense of a wider range of social and economic interactions using the lens of agency theory.

It is noteworthy that one stream of research on agency theory where this relationship between asymmetric information (though not adverse selection) and contract design has received some attention is the literature on professional services (Sharma 1997). Professional experts exercise considerable "power" (Freidson 1970; Larson 1977) in the professional-client relationship even though they are service-provider agents in relation to the uninformed clients (principals). Their high level of specialization and their social and economic privileges have long imparted professionals with authority and autonomy over the design of the client-professional principal-agent contract. To be sure, professionals differ from scam perpetrators. The prototypical professional service involves serving the interest of clients, in exact opposition to the prototypical consumer scam, which involves manipulating and taking advantage of victims' trust. Nevertheless, the shared structure of 
information and interaction exhibit a uniform adverse selection structure, as well as a lack of meaningful control on the part of principals (uninformed clients/victims). ${ }^{9}$

\section{Conclusion}

This paper develops a theoretical perspective for studying the structure of information and the role of perpetrators as agents in consumer scams. The multidisciplinary literature on consumer scams has thus far focused primarily on individual characteristics and specific scam contexts, and less so on the general structure of information in scam relationships. We have provided an agency-theoretic approach to the study of scam relationships and their adverse selection problems. Agency theory's attraction in this context lies in its capacity to help us think clearly about the structure of information that facilitates manipulative scamming relationships. Specifically, the interaction-whereby one person (the agent) is supposed to carry out certain tasks on behalf of the other (the principal) - is appropriate for the study of consumer scams since this is precisely the principal-agent mould/narrative the victims fall for.

Recall the Nigerian general email scam mentioned at the outset of the paper. How might our proposed approach explain that scam? The victim is the uninformed principal and the email sender is the informed agent. The email sender prepares a principal-agent mould (resembling wardship), and embeds it with adverse selection. The principal (victim) encounters adverse selection through (1) a failure of observation, since she may not possess enough information about the email sender (the perpetrator's criminal record, for example), and (2) a failure of judgment, since the victim may not have the ability to assess investment opportunities, the military's access to wealth, and the political situation in Nigeria. Notice that the failures of judgment and observation in the structure of information occur before the agency contract commences

\footnotetext{
9 What we propose as an interesting and distinct feature of contract design in victim-perpetrator agency interactions is a routine feature of two-player game-theoretic analyses. There, in any given game, player 1 or player 2 may offer and design the contract (Osborne and Rubinstein 1994). This would suggest that agency theory is not the most appropriate theoretical lens through which to analyse consumer scams. A similar line of argument might suggest that our observation about scam contract design is not cause for revising agency theory's theoretical assumption. Rather, agency theory may not be as appropriate as game theory in explaining the scam phenomenon. We agree that there is much to learn about consumer scams through game theory. In fact, the approach to agency theory we have been drawing upon is a simplified game-theoretic approach to a specific class of interactions: those between principals and agents. Reconsidering the assumption of contract design in the principal-agent model is thus appropriate given the existing theoretical links between the literatures on game theory and agency theory.
}

(adverse selection): the email sender is lying about her honourable intentions, but the victim cannot see through this before they send off their savings. Although the principal (victim) is technically in charge, the impact of the adverse selection relationship renders this control merely symbolic. This wardship relationship entangles victims in severe adverse selection and provides opportunities to perpetrators for defrauding their victims.

Beyond enhancing our understanding of the phenomenon of consumer scams, this paper has questioned a core assumption in agency theory. While contract design is the formal prerogative of the principal in principal-agent models, in practice this role appears to be under the influence and guidance of the agent (the scam perpetrator) in consumer scams. This structure parallels the professional-client agency relationship, where the informed professional is an agent who acts on behalf of uninformed clients, and exercises considerable authority over the terms and structure of the interaction. This is a largely neglected line of investigation in the literature on agency theory, unlike the more popular assumptions of opportunism and self-interest/expected utility maximization that have been subject to extensive critical debate. A promising area for future research might involve a comparative study of these two different contexts and their shared adverse selection/contract design features, as part of a larger study of the agency structure of consumer services in modern developed economies.

Some agency theorists have argued for a separation between agency roles and employment functions. After all, an employee might fulfil the agent's or the principal's role at any given time, depending on the context. In a similar vein, we question the automatic assignment of the function of control and authority to principals, as opposed to agents, in the principal-agent model. Our analysis of the consumer scam context has provided some evidence in support of this line of argument. This revised stance about contract design has interesting implications for ongoing debates about the normative structure and justification of principal-agent relationships, for example in relation to the concept of authority (e.g. Donaldson 2012; Heath 2009).

Open Access This article is distributed under the terms of the Creative Commons Attribution 4.0 International License (http://crea tivecommons.org/licenses/by/4.0/), which permits unrestricted use, distribution, and reproduction in any medium, provided you give appropriate credit to the original author(s) and the source, provide a link to the Creative Commons license, and indicate if changes were made.

\section{References}

(ABS) Australian Bureau of Statistics. (2012). Personal fraud 2010-2011. ABS cat. no. 4528.0. Canberra: ABS. http://www. 
abs.gov.au/AUSSTATS/abs@.nsf/Lookup/4528.0Main+Fea tures12010-2011? OpenDocument. Accessed Dec 12, 2015.

Akerlof, G. A., \& Shiller, R. J. (2015). Phishing for phools: The economics of manipulation and deception. Princeton: Princeton University Press.

Alchian, A. A., \& Demsetz, H. (1972). Production, information costs, and economic organization. The American Economic Review, 62(5), 777-795.

Aleem, A., \& Antwi-Boasiako, A. (2011). Internet auction fraud: The evolving nature of online auctions criminality and the mitigating framework to address the threat. International Journal of Law, Crime, and Justice, 39, 140-160.

Arrow, K. J. (1963). Uncertainty and the welfare economics of medical care. American Economic Review, 53(5), 941-973.

Arrow, K. J. (1985). The economics of agency. In J. W. Pratt \& R. J. Zeckhauser (Eds.), Principals and agents: The structure of business. Boston: Harvard Business School.

Bergen, M., Dutta, S., \& Walker, O. (1992). Agency relationships in marketing: A review of the implications and applications of agency and related theories. Journal of Marketing, 56, 1-24.

Best, D. (2012). Online dating scammer made off with her money and heart. Huffington Post, October 25. http://www.huffingtonpost. com/2012/10/25/debbie-best-online-dating-scam_n_1959219. html. Accessed May 8, 2014.

Bolton, P., \& Dewatriopont, M. (2005). Contract theory. Cambridge, MA: MIT Press.

Bosse, D., \& Phillips, R. (2016). Agency theory and bounded selfinterest. Academy of Management Review, 41(2), 276-297.

Button, M., Lewis, C., \& Tapley, J. (2009). Fraud typologies and victims of fraud. London: Office of Fair Trading.

Carter, E. (2015). The anatomy of written scam communications: An empirical analysis. Crime, Media, Culture, 11(2), 89-103.

Chen, J., Cumming, D., Hou, W., \& Lee, E. (2016). Does the external monitoring effect of financial analysts deter corporate fraud in China? Journal of Business Ethics, 134, 727-742.

Chua, C. E. H., \& Wareham, J. (2008). Parasitism and Internet auction fraud: An exploration. Information and Organization, 18, 303-335.

Cialdini, R. B. (1984). Influence: How and why people agree to things. New York: William Morrow.

Cialdini, R. B. (2007). Influence: The psychology of persuasion. New York: HarperCollins.

Cohen, C. A. (2006). Consumer fraud and the elderly: A review of Canadian challenges and initiatives. Journal of Gerontological Social Work, 46(3-4), 137-144.

Coric, B. (2011). The financial accelerator effect: Concept and challenges. Financial Theory and Practice, 35(2), 171-196.

Cross, C., Smith, R. G., \& Richards, K. (2014). Challenges of responding to online fraud victimisation in Australia. Trends and Issues in Crime and Criminal Justice, 474. http://eprints.qut.edu. au/72186/1/tandi474.pdf. Accessed Dec 10, 2015.

Darby, M. R., \& Karni, E. (1973). Free competition and the optimal amount of fraud. Journal of Law and Economics, 16, 67-88.

Dees, J. G. (1992). Principals, agents and ethics. In N. E. Bowie \& R. E. Freeman (Eds.), Ethics and agency theory (pp. 25-58). Oxford: Oxford University.

Donaldson, T. (2012). The epistemic fault line in corporate governance. Academy of Management Review, 37(2), 256-271.

Eisenberg, M. A. (1976). The structure of the corporation: A legal analysis. Boston: Little, Brown \& Company.

Eisenhardt, K. M. (1989). Agency theory: An assessment and review. Academy of Management Review, 14(1), 57-74.

Evans, B. D., Russell, D. T., \& Sager, T. W. (2013). Operational, legal and tax issues in life settlement transactions. Journal of Insurance Regulation, 32(1), 101-118.
Fama, E. F. (1980). Agency problems and the theory of the firm. Journal of Political Economy, 88, 288-307.

Fama, E. F., \& Jensen, M. C. (1983). Separation of ownership and control. Journal of Law and Economics, 26, 327-349.

FBI (U.S. Federal Bureau of Investigation). (1984). Uniform crime reporting handbook: Summary system (pp. 24-25). Washington, DC: U.S. Government Printing Office.

Fischer, P., Lea, S. E. G., \& Evans, K. M. (2013). Why do individuals respond to fraudulent scam communications and lose money? The psychological determinants of scam compliance. Journal of Applied Social Psychology, 43(10), 2060-2072.

Francis, D. (1997). Bre-X: The inside story. Toronto: Key Porter.

Frankel, T. (2012). The Ponzi scheme puzzle: A history and analysis of con artists and their victims. Oxford: Oxford University Press.

Freidson, E. (1970). Professional dominance. Chicago: Aldine.

FTC (Federal Trade Commission). (2016). Consumer sentinel network: Data Book for 2015. https://www.ftc.gov/system/files/ documents/reports/consumer-sentinel-network-data-book-janu ary-december-2015/160229csn-2015databook.pdf. Accessed Jan 22, 2017.

Gabaix, X., \& Laibson, D. (2006). Shrouded attributes, consumer myopia, and information suppression in competitive markets. The Quarterly Journal of Economics, 121(2), 505-540.

Ganzini, L., McFarland, B., \& Bloom, J. (1990). Victims of fraud: Comparing victims of white collar and violent crime. Bulletin of the American Academy of Psychiatry and Law, 18, 55-63.

Ghent, A., Torous, W., \& Valkanov, R. (2016). Complexity in structured finance: Financial wizardry or smoke and mirrors? Social Science Research Network. http://papers.ssrn.com/sol3/ papers.cfm?abstract_id=2325835. Accessed Aug 2, 2016.

Goold, D., \& Willis, A. (1997). The Bre-X fraud. Toronto: McClelland and Stewart.

Hart, O., \& Holmsrom, B. (1987). The theory of contracts. In T. Bewley (Ed.), Advances in economics and econometrics, econometric society monographs, fifth world congress (pp. 71-155). Cambridge: Cambridge University.

Heath, J. (2009). The uses and abuses of agency theory. Business Ethics Quarterly, 19(4), 497-528.

Holtfreter, K., Reisig, M., \& Pratt, T. (2008). Low self-control, routine activities and fraud victimization. Criminology, 46(1), 189-220.

Husted, B. W. (2007). Agency, information, and the structure of moral problems in business. Organization Studies, 28(2), 177-195.

Hutchinson, B. (1998). Fool's gold: The making of a global market fraud. Toronto: Alfred A. Knopf.

Isacenkova, J., Thonnard, O., Costin, A., Francillon, A., \& Balzarotti, D. (2014). Inside the scam jungle: A closer look at 419 scam email operations. EURASIP Journal on Information Security, 2014(1), 1-18.

Jensen, M. C. (1983). Organization theory and methodology. Accounting Review, 50, 319-339.

Jensen, M. C., \& Meckling, W. H. (1976). Theory of the firm: Managerial behavior, agency costs and ownership structure. Journal of Financial Economics, 3(4), 305-360.

Johnson, E. (2016). Airbnb-Craigslist rental scam dupes Vacouverites out of $\$ 1000, C B C$ News, February 22. http://www.cbc.ca/news/ canada/british-columbia/airbnb-rental-scam-dupes-vancouver ites-1.3454533. Accessed Jan 2017.

Kahneman, D., \& Tversky, A. (1984). Choices, values, and frames. American Psychologist, 39(4), 341-350.

Kane, E. J. (2003). Continuing dangers of disinformation in corporate accounting reports, Working Paper 9634. Cambridge, MA: National Bureau of Economic Research. 
Knight, F. H. (1921). Risk, uncertainty and profit. Boston: Houghton Mifflin.

Konte, M., Feamster, N., \& Jung, J. (2009). Dynamics of online scam hosting infrastructure. In International conference on passive and active network measurement (pp. 219-228). Berlin: Springer.

Kurland, N. B. (1991). The ethical implications of the straightcommission compensation system: An agency perspective. Journal of Business Ethics, 10(10), 757-766.

Laffont, J. J., \& Martimort, D. (2009). The theory of incentives: The principal-agent model. Princeton, NJ: Princeton University.

Lambert, P. (2000). Knave of diamonds? People Magazine, February $7 . \quad \mathrm{http} / / / \mathrm{www}$. people.com/people/archive/article/ 0,,20130418,00.html. Accessed Apr 14, 2014.

Langenderfer, J., \& Shimp, T. A. (2001). Consumer vulnerability to scams, swindles, and fraud: A new theory of visceral influences on persuasion. Psychology and Marketing, 18, 763-783.

Langton, L., \& Baum, K. (2010). Identity theft reported by households, 2007: Statistical tables. Washington, DC: US Department of Justice, Office of Justice Programs, Bureau of Justice Statistics. https://www.bjs.gov/content/pub/pdf/itrh0510. pdf. Accessed March 3, 2017.

Larson, M. S. (1977). The rise of professionalism: A sociological analysis. Berkeley, CA: University of California Press.

Lea, S., Fischer, P. \& Evans, K. (2009). The psychology of scams: Provoking and committing errors of judgment. Report for the Office of Fair Trading. www.oft.gov.uk/shared_oft/reports/con sumer_protection/oft1070.pdf. Accessed Dec 1, 2015.

Levi, M. (2008). Organized fraud and organizing frauds: Unpacking research on networks and organization. Criminology and Criminal Justice, 8(4), 389-419.

Marschak, J. (1955). Elements for a theory of teams. Management Science, 1, 127-137.

Maskin, E., \& Riley, J. (1984). Monopoly with incomplete information. Rand Journal of Economics, 15, 171-196.

Mears, D. P., Reisig, M. D., Scaggs, S., \& Holtfreter, K. (2014). Efforts to reduce consumer fraud victimization among the elderly: The effect of information access on program awareness and contact. Crime and Delinquency, 62(9), 1235-1259.

Milgrom, P., \& Roberts, J. (1992). Economics, organization and management. Upper Saddle River, NJ: Prentice Hall.

Mitnick, B. M. (1992). The theory of agency and organizational analysis. In B. M. Mitnick (Ed.), Ethics and agency theory: An introduction (pp. 75-96). New York: Oxford University Press.

Mitnick, B. M. (1996). The hazards of agency. In B. M. Mitnick (Ed.), The theory of agency. Cambridge: Cambridge University Press forthcoming. http://papers.ssrn.com/sol3/papers.cfm?abstract id=1021332. Accessed Dec 1, 2015.

Murray, R. (2013). One in ten online dating profiles is fake: See the most common characteristics of fraudsters. New York Daily News, May 8. http://www.nydailynews.com/life-style/spot-fakeonline-dating-profile-article-1.1338600. Accessed Apr 16, 2014.

Naylor, R. T. (2007). The alchemy of fraud: Investment scams in the precious metals mining business. Crime, Law, and Social Change, 47(2), 89-120.

Naylor, R. T. (2010). The underworld of gemstones: Hot rocks, cold cash. Crime, Law, and Social Change, 53, 307-327.

Newton, L. (1992). Agents for the truly greedy. In N. E. Bowie \& R. E. Freeman (Eds.), Ethics and agency theory. Oxford: Oxford University Press.

NFA (National Fraud Authority. (2013). Annual fraud indicator. https://www.gov.uk/government/uploads/system/uploads/ attachment_data/file/206552/nfa-annual-fraud-indicator-2013. pdf. Accessed Dec 9, 2015.

Nwogugu, M. (2004). Legal, economic and psychological issues of accounting for employee stock options. Managerial Auditing Journal, 19(9), 1079-1118.

OFT (Office of Fair Trading). (2006). Research on impact of mass marketed scams. London: OFT.

Osborne, M. J., \& Rubinstein, A. (1994). A course in game theory. Cambridge, MA: MIT Press.

Pinsker, D. M., McFarland, K., \& Stone, V. E. (2011). The social vulnerability scale for older adults: An exploratory and confirmatory factor analytic study. Journal of Elder Abuse and Neglect, 23(3), 246-272.

Pratt, J. W., \& Zeckhauser, R. J. (1985). Principals and agents: The structure of business. Boston: Harvard Business School.

Ramesh, G., Krishnamurthi, I., \& Kumar, K. S. S. (2014). An efficacious method for detecting phishing webpages through target domain identification. Decision Support Systems, 61, $12-22$.

Rasmussen, E. (2007). Games and information (4th ed.). Oxford: Blackwell.

Ross, S. A. (1973). The economic theory of agency: The principal's problem. American Economic Review, 62(2), 134-139.

Ross, S., \& Smith, R. G. (2011). Risk factors for advance fee fraud victimisation, Report 420. Canberra: Australian Institute of Criminology.

Salanié, B. (2005). The economics of contracts. Cambridge, MA: MIT Press.

Sharma, A. (1997). Professional as agent: Knowledge asymmetry in agency exchange. Academy of Management Review, 22(3), $758-798$

Smith, A. (2009). Nigerian scam e-mails and the charms of capital. Cultural Studies, 23(1), 27-47.

Tippett, R. A. (2014). Lender deception as a response to moral hazard. Journal of Economics, 113, 59-77.

Titus, R. M., \& Gover, A. R. (2008). Personal fraud: The victims and the scams. Crime Prevention Studies, 12, 133-151.

Trahan, A., Marquart, J. W., \& Mullings, J. (2005). Fraud and the American dream: Toward an understanding of fraud victimization. Deviant Behavior, 26(6), 601-620.

U.S. v. Hasson. (2003). 11th Circuit Court of Appeal. Docket No. 99-08063-CR-JLK.

Wall, D. S. (2007). Cybercrime: The transformation of crime in the information age. London: Polity Press.

Walsh, J. P., \& Seward, J. K. (1990). On the efficiency of internal and external corporate control mechanisms. Academy of Management Review, 15(3), 421-458.

White, H. (1985). Agency as control. In J. Pratt \& R. Zeckhauser (Eds.), Principia and agents: The structure of business (pp. 187-212). Boston: Harvard Business School.

Whitty, M. T. (2013). The scammers persuasive techniques model: Development of a stage model to explain the online dating romance scam. British Journal of Criminology, 53(4), 665-684.

Whitty, M. T. (2015). Anatomy of the online dating romance scam. Security Journal, 28(4), 433-455.

Whitty, M. T., \& Buchanan, T. (2012). The online dating romance scam: A serious crime. Cyber Psychology, Behaviour, and Social Networking, 15(3), 181-183.

Wilson, C. (2000). Jeweler charged in $\$ 80$ million scam. Fort Lauderdale Sun-Sentinel, January 12. http://articles.sun-sentinel. com/2000-01-12/news/0001120103_1_hasson-jewels-federalcourt. Accessed Apr 15, 2014. 